de Gruyter Lehrbuch

Hüttner - Betriebswirtschaftslehre 



\section{Manfred Hüttner}

\section{Betriebswirtschaftslehre Einführung und Überblick}

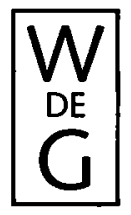

Walter de Gruyter · Berlin · New York 1990 


\section{Dr. Manfred Hüttner}

Professor am Fachbereich Wirtschaftswissenschaften

der Universität Bremen

Mit 140 Darstellungen

\section{CIP-Titelaufnahme der Deutschen Bibliothek}

\section{Hüttner, Manfred:}

Betriebswirtschaftslehre : Einführung und Überblick / Manfred Hüttner. Berlin ; New York : de Gruyter, 1990

(De-Gruyter-Lehrbuch)

ISBN 3-11-012336-3

(을 Gedruckt auf säurefreien Papier, das die US-ANSI-Norm über Haltbarkeit erfüllt.

(c) Copyright 1990 by Walter de Gruyter \& Co., D-1000 Berlin 30.

Dieses Werk einschließlich aller seiner Teile ist urheberrechtlich geschützt. Jede Verwertung außerhalb der engen Grenzen des Urheberrechtsgesetzes ist ohne Zustimmung des Verlages unzulässig und strafbar. Das gilt insbesondere für Vervielfältigungen, Übersetzungen, Mikroverfilmungen und die Einspeicherung und Verarbeitung in elektronischen Systemen.

Printed in Germany.

Satz: Knipp Textverarbeitung, Wetter / Druck: Kupijai + Prochnow, Berlin Buchbinderische Verarbeitung: Dieter Mikolai, Berlin 